\title{
ENSINO DE HISTÓRIA E USOS DAS DIFERENÇAS: CONSTRUINDO CAMINHOS, TRILHANDO POSSIBILIDADES ${ }^{1}$ \\ TEACHING HISTORY AND THE USES OF DIFFERENCES: BUILDING PATHS, TRACKING POSSIBILITIES
}

Fabiana Francisca Macena²

Resumo: Neste artigo, propomos uma reflexão acerca de nossas experiências enquanto professora/pesquisadora junto a alunos e alunas do ensino fundamental em uma escola pública do Distrito Federal. Trata-se de pensar o ensino de História, suas possibilidades e a potência de práticas pedagógicas que tenham como ponto de partida o questionamento dos mecanismos e instituições que fixam identidades e constroem diferenças, sobretudo as de raça e gênero, promovendo a desnaturalização de tais construtos e a criação de outras representações, outras narrativas abertas ao múltiplo, ao plural.

Palavras-chave: Ensino de História; Gênero; Raça; Arte.

Abstract: In this article, we propose a reflection on our experiences as a teacher/researcher with public school elementary students in Brasilia Federal District/Brasil. The discussion goes arounds thinking about the History teaching, the pedagogical practices possibilities and power that have as their starting point the questioning of the mechanisms and institutions that establish identities and build differences, especially those of race and gender, promoting the denaturalization of such constructs and the creation of other representations and narratives open to the multiple, to the plural.

Key-words: History Teaching; Gender; Race; Art.

O trabalho da narrativa é, por isso mesmo, o de ordenar, dar forma e tornar significativo um conjunto disperso de experiências e vivências segundo certos padrões e dispositivos capazes de serem apreendidos por uma comunidade de leitores/intérpretes. Mas, ao fazê-lo, opera necessariamente a partir de um trabalho de domesticação desse segundo necessidades e demandas que

\footnotetext{
${ }^{1}$ Meus sinceros agradecimentos à equipe do Centro de Ensino Fundamental 18 de Ceilândia, pela parceria e pelo apoio em cada uma das atividades desenvolvidas. Afinal, o ato de ensinar é, antes de qualquer coisa, um ato coletivo. E, principalmente, aos/às estudantes dos sétimos anos do ensino fundamental. As reflexões expostas neste artigo trazem muito dos nossos diálogos e inquietações ao longo do ano letivo de 2019. Também agradeço às/aos pareceristas anônimos pela leitura atenta, pelas sugestões e pelos apontamentos realizados, que possibilitaram a versão final deste artigo.

${ }^{2}$ Doutora em História pela Universidade de Brasília (UnB). Professora da Secretaria de Educação do Distrito Federal (SEDF)
} 
Dossiê: Ensino de História, História das Mulheres e Desigualdades Sociais no Brasil não são evidentemente as do próprio passado. (GUIMARÃES, 2006, p.47).

Ao refletir sobre o fazer histórico, sobre a tarefa de conferir sentidos e significados aos eventos pretéritos e sobre a narrativa resultante de tal operação, segundo critérios e padrões que permitam sua apreensão por uma comunidade de historiadores e historiadoras, Manoel Luiz Salgado Guimarães aponta para aquele que seria um dos aspectos centrais dessa narrativa: o controle, a ordenação e a domesticação do passado. O esforço em tornar dizível e inteligível os afetos, as paixões e os sentimentos; de dar forma e conferir sentidos às experiências vividas de acordo com necessidades do tempo presente. Uma relação tensa entre o vivido e o narrado, "relação tanto mais necessária quanto indispensável para o partilhar das experiências vividas" (GUIMARÃES, 2006, p.46).

Embora minhas pretensões sejam bem mais modestas do que as do referido autor, suas considerações orientam o meu esforço em historicizar um "conjunto disperso de experiências e vivências". Neste caso, aquelas relacionadas ao meu fazer como professora do ensino fundamental - anos finais - na Secretaria de Estado de Educação do Distrito Federal (SEDF). Neste artigo, procuro tornar coerente uma série de experiências e de vivências dispersas, precisar minha própria localização no mundo enquanto sujeito, a minha "topografia de interesses", para usar a feliz expressão de Michel de Certeau. Aliás, se, como afirma este historiador, toda pesquisa historiográfica estaria "articulada a um lugar de produção sócio-econômico, político e cultural" (CERTEAU, 2011, p.47), procuro precisar ao longo deste texto meu lugar de fala, apresentar uma possibilidade de leitura de algumas experiências que possibilitam a minha existência como professora/historiadora em uma escola pública do Distrito Federal.

Vivências de alguém que tem construído um percurso distinto do que comumente se espera daqueles/as que percorrem os caminhos da pósgraduação em História no Brasil. Assim como muitos e muitas colegas de ofício, que trilham o mestrado e o doutorado a fim de alcançar a docência em universidades públicas, também investi em tais etapas, incluso o pós- 
Dossiê: Ensino de História, História das Mulheres e Desigualdades Sociais no Brasil doutoramento, com o mesmo objetivo, vivenciando, inclusive, algumas experiências como docente no ensino superior. Todavia, este trajeto foi alterado em 2017, quando, após ser aprovada em concurso público, ingressei na Secretaria de Estado de Educação do Distrito Federal e cheguei às salas de aula do ensino fundamental.

Tal mudança de itinerário não foi fácil e muito menos uma escolha óbvia. Foi repleta de inquietações e de inseguranças. Afinal, muitos e conhecidos são os impasses e os desafios enfrentados por aqueles e aquelas que atuam na educação básica: desvalorização profissional, falta de infraestrutura, ausência de engajamento das famílias e da sociedade no processo educativo, para citar alguns. Além disso, a opção pela educação básica, sobretudo em seus anos finais, ainda é escolha questionada por muitos, haja vista, como argumenta Diva Muniz, os assujeitamentos operados, as representações construídas que reafirmam "a divisão social do trabalho, com suas hierarquizações quanto aos locais de produção e de transmissão do saber." (MUNIZ, 2011, p.253-254). Discurso que naturaliza uma relação assimétrica e historicamente estabelecida entre o espaço da pós-graduação, da universidade e o espaço escolar.

Ainda na década de 1990, Selva Guimarães Fonseca apontava para tal hierarquização e para a persistência de um discurso que sublinhava a função transmissora da escola. Embora naquele momento emergisse uma produção acadêmica que questionava tais construções discursivas e que defendia a noção de saber escolar, a autora argumentava que este discurso novo "mistura-se com uma questão de fundo que permanece: a universidade produz um dado conhecimento 'necessário' à cultura e este continuará sendo imposto às escolas, a quem cabe a tarefa de socializá-los." (FONSECA, 1993, p.123). De lá para cá, a produção acadêmica no Brasil sobre o ensino de história cresceu consideravelmente. Pesquisadores e pesquisadoras têm se debruçado sobre o tema a partir de diferentes fontes, abordagens e perspectivas teóricometodológicas. Ainda assim, mesmo com esta extensa produção, que problematiza a relação entre o conhecimento histórico acadêmico e o escolar, é possível perceber uma prática discursiva que sublinha a produção historiográfica realizada, em boa medida, no espaço das universidades, como referência para 
Dossiê: Ensino de História, História das Mulheres e Desigualdades Sociais no Brasil

a história ensinada, reafirmando a academia como espaço por excelência da pesquisa e da produção do conhecimento.

Tais persistências se fazem visíveis, dentre outras formas, nos questionamentos dos/das colegas de profissão, nas falas que sublinham o estranhamento com a minha presença em um espaço que, na leitura deles/delas, não é o meu. Afinal, como alguém que percorreu os caminhos da pós-graduação não está no espaço universitário? Como pode persistir e insistir em dar aulas para adolescentes dos anos finais do ensino fundamental? São construtos que indicam as relações de saber/poder existentes, que atravessam nossas formas de ver e dar a ler as relações entre o conhecimento acadêmico e o conhecimento escolar, que informam as representações sobre esses espaços de produção do conhecimento e que mantém a dicotomia existente entre pesquisa e ensino, universidade e escola.

Se reconhecemos que a escola se constitui como um espaço singular de produção do conhecimento, neste caso específico, o conhecimento histórico escolar, qual seria, portanto, o papel do/a professor/a de história junto aos/às estudantes? Que narrativas temos construído em nossa prática docente? Quais são os sentidos de ensinar e aprender tal componente curricular na atualidade? O ensino de história tem sido espaço de práticas questionadoras, desnaturalizadoras e libertárias? Embora não tenha respostas definitivas para todas estas perguntas, acredito no ensino de história e em seu potencial transformador, em nossas ações pedagógicas como atividades de busca constante por "destronar ídolos e deuses, que visa inquietar o pensamento e o poder, que se destina a nos libertar do peso do passado, de sua repetição mecânica e a-crítica.”, como defende Durval Muniz de Albuquerque Júnior (2007, p.185).

Nesta perspectiva, acreditamos que, assim como argumenta Ana Maria Monteiro, no espaço de nossas aulas e atividades pedagógicas, cabe a nós, professores e professoras,

trabalhar o "pensamento histórico" para o questionamento de verdades estabelecidas e busca da compreensão da historicidade da vida social. Novos saberes são construídos pelos alunos, saberes estes que, ao se constituírem como conhecimento cotidiano, e ao incorporar a dimensão 
Dossiê: Ensino de História, História das Mulheres e Desigualdades Sociais no Brasil

problematizadora e crítica, podem tornar-se instrumento de libertação, resistência. Mas pode também se manter como lugar para a legitimação de poderes instituídos, em perspectiva conservadora.

As definições e opções dos professores no seu fazer são fundamentais para marcar e orientar diferentes abordagens e encaminhamentos. (MONTEIRO, s/d, p.16).

Apostamos, portanto, na dimensão crítica do ensino de história e na possibilidade de construção de novos saberes, de um conhecimento histórico escolar libertador, aberto a outras leituras do social. Opção que problematiza e questiona o papel da escola na perpetuação das assimetrias, seu caráter padronizador e homogeneizador, seu distanciamento com relação às questões atuais e à sociedade que se pretende construir. Afinal, a escola é um dos espaços no qual as sociedades disputam as memórias possíveis sobre si mesmas, onde identidades são gestadas e saberes são legitimados, além de espaço de tensões e conflitos em torno da construção de representações do passado e pela projeção do futuro, como argumentam Mario Carretero, Alberto Rosa e María Fernanda González (2006, p.12-13).

Sendo assim, a partir da ação de estudantes e professores/professoras, o ensino de história pode se configurar como um "outro lugar", conforme o define Teresa de Lauretis: com a criação de novos espaços de discurso, reescrita de narrativas culturais e definição de termos em outra perspectiva. Nas palavras daquela autora, o "outro lugar" pode ser compreendido como:

\begin{abstract}
espaços nas margens dos discursos hegemônicos, espaços sociais entalhados nos interstícios das instituições e nas fendas e brechas dos aparelhos de poder-conhecimento. E é aí que os termos de uma construção diferente do gênero [e acrescento: também das relações étnico-raciais] podem ser colocados termos que tenham efeito e que se afirmem no nível da subjetividade e da auto-representação: nas práticas micropolíticas da vida diária e das resistências cotidianas que proporcionam agenciamento e fontes de poder ou investimento de poder [...]. (LAURETIS, 2004, p.237)
\end{abstract}

É nesta tensão entre os discursos hegemônicos e as críticas à ele feitas a partir dos discursos dos estudos feministas, de gênero e das relações étnicoraciais que compreendemos o ensino de história como locus da elaboração de 
Dossiê: Ensino de História, História das Mulheres e Desigualdades Sociais no Brasil

outras representações ${ }^{3}$, de novas possibilidades de leitura, distintos modos de ver e dar a ler o passado e o futuro, bem como da emergência de sujeitos e construção de identidades. Afinal, como afirma Denise Jodelet, toda representação "é uma forma de conhecimento" e são elaboradas para agir sobre o mundo e o outro (JODELET, 2001, p.32).

É por esta razão que propomos, em nossas "práticas micropolíticas da vida diária", em nosso trabalho pedagógico, problematizar os modos de ler e dar a ler a presença negra, sobretudo das mulheres negras, no conhecimento histórico escolar. Trata-se de questionar os mecanismos e instituições que fixam identidades e constroem diferenças, sobretudo as de raça e gênero, naturalizando desigualdades e impactando diretamente na construção das subjetividades.

Neste artigo, compartilhamos uma dessas experiências, em uma leitura a partir das margens, de um tema consolidado do currículo de História do ensino fundamental e de práticas discursivas tornadas clássicas: o Renascimento e as pinturas renascentistas, respectivamente. Estes artefatos culturais encontramse atravessados por relações de saber/poder e funcionam como importantes tecnologias, produtoras de efeitos homogeneizador, normatizador e disciplinador de comportamentos e relações sociais. Produzem representações que atravessam os indivíduos, naturalizando construtos, pois chegam até nós carregados de sentidos "que não sabemos como se constituíram e que no entanto significam em nós e para nós." (ORLANDI, 2007, p.20). Além disso, possuem função pedagógica, pois ensinam a interpretar as imagens e representações sociais de gênero e de raça. Ou seja, são tecnologias políticas, criadoras e modeladoras das maneiras de se pensar, agir e de significar. ${ }^{4}$

\footnotetext{
${ }^{3}$ Representações sociais entendidas, aqui, como "uma forma de conhecimento socialmente elaborado e compartilhado, com um objetivo prático, e que contribui para a construção de uma realidade comum a um conjunto social", conforme define Denise Jodelet (2001, p.22). Em outras palavras, trata-se de formas de conhecimento socialmente elaboradas e partilhadas, que criam também verdades, imagens, comportamentos, papéis sociais, hierarquias e normas que podem interferir no mundo, na constituição das identidades e nas relações sociais.

${ }^{4}$ Nos aproximamos, aqui, do pensamento de Michel Foucault, para o qual o poder não está no Estado, não ocupa um lugar específico, mas que é algo que funciona, que atravessa o tecido social, horizontal e verticalmente, que ocorre por meio de relações, que não apenas reprime, mas sobretudo cria. Sendo assim, pensamos aqui não a política institucionalizada, em que o poder seria sinônimo de Estado, mas uma política que ocorre no dia-a-dia, em todas as relações sociais, em suas hierarquizações, resistências, dominações. A maneira como o poder ocorre
} 


\section{HISTÓRIA}

Dossiê: Ensino de História, História das Mulheres e Desigualdades Sociais no Brasil

Todavia, mesmo que tais textos organizem os gestos de interpretação a partir de um "já dito", como nos lembra Eni Orlandi, sujeito, sentidos e discurso não estão prontos e acabados. Há aí espaço para a criatividade, ou seja, a

ruptura do processo de produção da linguagem, pelo deslocamento das regras, fazendo intervir o diferente, produzindo movimentos que afetam os sujeitos e os sentidos na sua relação com a história com a língua. Irrompem assim sentidos diferentes. (ORLANDI, 2007, p.37)

Nessa direção, ao interpretarem imagens renascentistas a partir de uma outra perspectiva, de outros referenciais, os/as estudantes colocam em conflito o já produzido e o que será elaborado. São instigados a compreender como tais objetos simbólicos produzem sentidos, promovendo a desnaturalização de construtos como gênero e raça. Nesta leitura que busca esvaziar a sacralidade de tais artefatos, os/as estudantes apropriam-se criativamente destes, sendo estimulados a produzir narrativas abertas ao múltiplo, ao plural, orientadas por outras representações sociais, ao mesmo tempo em que se constituem como sujeitos do conhecimento histórico escolar.

Ensino de história, raça e gênero: interrelações

Mais uma aula em uma turma de $7^{\circ}$ ano do ensino fundamental. O tema em pauta era a sociedade medieval, o modo como estava organizada, suas hierarquias e relações de poder, explicitada no que costumamos chamar de "sociedade das três ordens", e as representações sociais que asseguravam seu funcionamento. Em meio ao debate, vejo uma mão se erguer, pedindo a palavra. Sem pestanejar e de maneira muito firme, Júlia me questionou: afinal, por que não se fala de senhoras feudais? Na pergunta feita, outra se faz presente: por que tão pouco se fala das mulheres na Idade Média?

A pergunta de Júlia é válida para a Idade Média europeia, mas, também, para tantos outros momentos e espaços. É o questionamento de tantas outras

concretamente, "com sua especificidade, suas técnicas e suas táticas". (FOUCAULT, 2007, p.63). 
Dossiê: Ensino de História, História das Mulheres e Desigualdades Sociais no Brasil estudantes que não se veem representadas em uma narrativa ainda marcadamente eurocêntrica, escrita no masculino. Como um saber também atravessado por relações de poder, como todo saber, a história permanece pensada e escrita sob os códigos do patriarcado, tanto na produção acadêmica como no conhecimento histórico escolar.

Em relação a este último, pesquisas no campo da História das Mulheres, Estudos de Gênero e Estudos Feministas têm apontado e denunciado o uso político da diferença na criação/reafirmação de desigualdades e tornado visível e dizível o protagonismo de mulheres em diferentes momentos e espaços. Todavia, conforme sublinha Susane Oliveira, mesmo com os avanços produzidos em tais campos de pesquisa, ainda é possível perceber que tais narrativas não são compartilhadas no espaço escolar e que "as políticas educacionais para a igualdade de gênero no Brasil, nas últimas décadas, pouco atingem o ensino de história ministrado nas escolas." (OLIVEIRA, 2014, p.280). Persistências que, como sublinha a autora, promovem o silêncio sobre a atuação das mulheres na história, reafirmando concepções binárias e hierárquicas de gênero, estabelecendo desigualdades e violências.

Isso se torna ainda mais evidente e incômodo quando nos referimos às mulheres negras, às suas presenças na história. Presente, porém, invisível, o protagonismo negro na história foi silenciado por muito tempo tanto pela historiografia quanto pelo conhecimento histórico escolar, apagando sua presença da memória social. Afinal, como sublinham Mauro Cezar Coelho e Wilma de Nazaré Baía Coelho,

\begin{abstract}
A narrativa consagrada acerca de nossa formação como país e como nação elegeu a Europa como epicentro de nossa história e como nossa herança mais importante. Os povos africanos e indígenas comparecem à narrativa como elementos coadjuvantes, cuja participação é mais alegórica que determinante. (COELHO e COELHO, 2013, p.96).
\end{abstract}

Na tentativa de romper com tais narrativas fundadoras e já consagradas, destaca-se a lei 10.639/03, que estabelece a obrigatoriedade do ensino de história e cultura afro-brasileira no ensino fundamental e médio, e o papel exercido pela articulação dos movimentos negros em favor de sua aprovação. Cientes do papel das escolas na perpetuação das desigualdades raciais, estes 
Dossiê: Ensino de História, História das Mulheres e Desigualdades Sociais no Brasil

movimentos articulam-se, pelo menos desde a década de 1950, a fim de pressionar pela inserção do estudo da história do continente africano e dos africanos, a luta dos negros no Brasil, a cultura negra brasileira e o negro na formação da sociedade brasileira, temáticas contempladas pela redação final da lei. (SANTOS, 2005).

Os caminhos abertos por aquele texto legal promovem importante deslocamento, ao ressaltar o protagonismo de outros sujeitos, estimulando a reconfiguração da memória histórica acerca de nossa formação social, ainda eminentemente eurocêntrica. Todavia, é perceptível as limitações quanto à sua aplicação, como tem destacado alguns autores e autoras (SANTOS, 2005; SOUZA, 2012; COELHO e COELHO, 2013), indicando "uma certa falta de compromisso vigoroso com a sua execução e, principalmente, com sua a eficácia" (SANTOS, 2005, p.34).

Em meio às ações tímidas de implementação da lei, percebe-se o silêncio que ainda impera em torno do protagonismo de mulheres negras. Afinal, como argumenta Bebel Nepomuceno, embora no século XX sejam percebidos alguns avanços nas lutas femininas pelo direito a ter direitos, tais conquistas não ocorreram do mesmo modo para todas, pois mulheres

de grupos sociais distintos viveram-na de maneiras diferentes e ritmos variados. Partiram de patamares desiguais $e$, no desenrolar dos acontecimentos, não caminharam juntas nem no mesmo passo, com determinadas situações de nítidos privilégios para umas e exclusão para outras. (NEPOMUCENO, 2012, p.382-383).

Exclusões que atingiram (e ainda atingem) diretamente as mulheres negras e que são percebidas, inclusive, no ensino de história. Suas presenças ainda se fazem pouco visíveis e dizíveis, dada sua dupla invisibilidade: de gênero e de raça. ${ }^{5}$ Sofrendo concomitantemente com o racismo e o sexismo, as

\footnotetext{
${ }^{5}$ No uso que fazemos aqui do conceito de raça, compartilhamos da definição elaborada por Antonio Sérgio Alfredo Guimarães, para quem raças são "construtos sociais, formas de identidade baseadas numa ideia biológica errônea, mas eficaz, socialmente, para construir, manter e reproduzir diferenças e privilégios. Se as raças não existem num sentido estritamente realista de ciência, ou seja, se não são um fato do mundo físico, são, contudo, plenamente existentes no mundo social, produtos de formas de classificar e de identificar que orientam as ações dos seres humanos." (GUIMARÃES, 1999, p.153). Quanto à categoria gênero, é compreendida tal como define Joan Scott, isto é, como "saber que estabelece o significado para as diferenças sexuais" e fundamenta "as relações sociais fundadas sobre as diferenças
} 
Dossiê: Ensino de História, História das Mulheres e Desigualdades Sociais no Brasil mulheres negras muitas vezes não ocupam a posição de sujeitos, permanecendo fora da ordem do discurso, juntamente com suas experiências, resistências, problemas e demandas, que parecem não existir. Indício de tal invisibilidade é o silêncio presente nos livros didáticos de história, como tem sido sinalizado por pesquisadores e pesquisadoras (CARVALHO, 2006; MESQUITA e SCHIAVON, 2013; MONTEIRO, 2016).

Tal silêncio, discursivamente produzido, explicita os sentidos políticos, as relações de saber/poder que orientam os temas, os assuntos e as abordagens considerados dignos de figurar nas páginas dos livros didáticos, nas quais o protagonismo de mulheres negras pouco aparece ou delas estão excluídas. Trata-se de ausência informada por uma leitura do social em que o biológico ainda delimita o lugar das mulheres de cor no mundo, suas possibilidades de ação, estabelecendo diferenças e hierarquizações. Nessa política de silenciamento, é negada às mulheres negras a posição de sujeitos históricos, o protagonismo e o agenciamento de suas próprias vidas.

Ao destacar as potencialidades das reflexões produzidas no campo da história das mulheres, estudos de gênero e estudos feministas, aliados aos debates sobre as questões étnico-raciais, operamos o questionamento dos fundamentos da história ensinada, sinalizando para outras possibilidades de leitura do social. Desta forma, ao reconhecermos as conexões entre raça e gênero, as semelhanças, diferenças e entrelaçamentos dessas duas formas de injustiça, enfatizamos as especificidades das experiências de vida, das representações e da construção das identidades de mulheres negras. Faz-se necessário, como argumenta Sandra Azerêdo, compreender "que raça, assim como gênero, se constitui em relações de poder e, portanto, determina tanto a vida das mulheres e homens brancos como a de homens e mulheres pretos." (AZERÊDO, 1994, p.204).

$\mathrm{Na}$ produção do conhecimento histórico escolar, tal opção analítica estimula o questionamento dos termos de uma narrativa hegemônica, eurocêntrica, masculina e branca, bem como as hierarquias por ela produzidas

percebidas entre os sexos (...) e as relações de poder" estabelecidas a partir desta distinção. (SCOTT, 1990). 


\section{HISTÓRIA}

Dossiê: Ensino de História, História das Mulheres e Desigualdades Sociais no Brasil

e reafirmadas, destacando distintas formas de ser e estar no mundo. Afinal, como argumenta Joan Pagès,

Existe, como es sabido, un importante déficit en el currículo, em los materiales curriculares y em las prácticas de enseñanza del papel de las mujeres em el passado y em el presente que pude tener importantes repercusiones em la educación de las jóvenes generaciones del siglo XXI. Em las jóvenes porque no ven qué papel han tenido en el passado las mujeres y no se identifican con el dos los varones. En los jóvenes porque este mismo hecho les lleva a pensar em la marginalidad de las mujeres en el passado y puede hacerles creer en los valores de la masculinidade, del androcentrismo y del machismo más violento. (PAGÈS, 2011, p.28)

De acordo com o autor, investir nas práticas e experiências de mulheres do passado vai além de suprir uma carência, criar um adendo à História. Tratase de pensar uma prática pedagógica que possibilite a criação de outras identidades e representações, orientada pelo estímulo à construção de relações cada vez mais igualitárias, alicerçadas no respeito ao outro. Mas é preciso ir além. É preciso problematizar as formas, os mecanismos e as instituições que garantem o processo de diferenciação e de transformação das diferenças em desigualdades. Compreender que tais classificações, que operam inclusões e exclusões, são discursivamente produzidas e constantemente reafirmadas, sobretudo pelo conhecimento histórico escolar. Concordamos com Tomaz Tadeu da Silva, para quem é crucial, antes "de tolerar, respeitar e admitir a diferença, é preciso explicar como ela é ativamente produzida." (SILVA, 2014: 99-100)

Nessa direção, para além da tolerância e respeito à diversidade e ao diferente, da indicação de sua existência, é preciso analisar a sua produção e naturalização, indicando que não são dados ou fatos da vida social, mas produtos de relações de poder, com implicações políticas. Cientes de tais construtos, novas possibilidades de leitura, em que outros sujeitos se tornem visíveis e suas histórias dizíveis, podem ser elaboradas. 


\section{HISTÓRIA}

Dossiê: Ensino de História, História das Mulheres e Desigualdades Sociais no Brasil

Releituras renascentistas sob uma perspectiva afro-brasileira: construindo outras narrativas

$\mathrm{Na}$ tentativa de tornar visível e dizível o protagonismo negro, particularmente o de mulheres negras, é que localizamos a proposta "Releituras renascentistas sob uma perspectiva afro-brasileira", trabalho desenvolvido ao longo do ano letivo de 2019 com estudantes de nove turmas dos sétimos anos do ensino fundamental. A partir de um tema tradicional do currículo, o Renascimento, estimulamos o questionamento da exclusão e da negação das narrativas negras, sobretudo no campo das artes, e a construção de outras possibilidades de leitura, visibilizando outras histórias e protagonistas. Estimulamos, desta forma, o enegrecimento de obras artísticas com o uso de referências provenientes da história e da cultura africana e afro-brasileira. Afinal, concordamos com Nilma Lino Gomes, para quem:

\footnotetext{
Muito mais do que um conteúdo curricular, a inserção da discussão sobre a África e a questão do negro no Brasil nas escolas da educação básica têm como objetivo promover o debate, fazer circular a informação, possibilitar análises políticas, construir posturas éticas e mudar o nosso olhar sobre a diversidade. (GOMES, 2008, p.81)
}

Ou seja, trata-se de repensar a prática pedagógica e o ensino de história, a partir de uma abordagem voltada para as relações étnico-raciais, cujo propósito é refletir sobre a construção das diferenças, das desigualdades raciais e de gênero, apontando para outras possibilidades de leitura e de construção do social. Uma prática que promova a desconstrução de uma narrativa de viés eurocêntrico, racista e androcêntrico, que fortaleça o conhecimento sobre a história e a cultura africana e afro-brasileira. Uma educação das relações étnicoraciais que, de acordo com a autora, estimule os/as estudantes à compreensão e à "desnaturalização das desigualdades e, ao fazê-lo, tornar-se-ão sujeitos da sua própria vida e da sua história". (GOMES, 2008, p.83)

Tendo isto em vista, a atividade foi executada em três etapas. Na primeira delas, os/as estudantes deveriam pesquisar a respeito de algumas obras 
Dossiê: Ensino de História, História das Mulheres e Desigualdades Sociais no Brasil

renascentistas previamente selecionadas ${ }^{6}$, obtendo informações como ano/período em que foram realizadas, tema, obras de referências, bem como dados sobre seus respectivos autores, tais como suas origens, seus mestres e influências. Nessa direção, o objetivo era aproximar alunas e alunos da produção artística dos séculos XV e XVI, possibilitando a compreensão das condições de produção de seus autores e dos sentidos inscritos nessas obras. Além disso, o incentivo à pesquisa das/dos estudantes encontra-se articulado tanto ao processo de aquisição de competências e habilidades próprias dessa etapa do ensino fundamental, como a uma "outra postura ante o conhecimento investigativa, curiosa, questionadora, problematizadora. Um caminho possível para descobertas, estabelecimento de relações e construção de conhecimentos", conforme sublinha Cláudia Sapag Ricci (2007, p.11).

Cientes das particularidades das obras selecionadas e das características que permitem integrá-las a um movimento artístico denominado de renascentista, avançamos para a segunda etapa de nossa proposta: a problematização do silêncio e da negação sobre/das narrativas negras, sobretudo no campo das artes; o questionamento, portanto, da construção da diferença e das relações de poder dela provenientes, suas hierarquizações e exclusões. Para esta discussão, utilizamos como mote o clipe da música Apeshit, lançada em 2018 pela dupla The Carters, formada por Beyoncé e Jay-Z.

Apeshit é potente como recurso didático por algumas razões. Primeiramente, por utilizar de dois discursos de grande apelo junto aos/às adolescentes: o musical e o visual. Uma narrativa que funciona como uma tecnologia social, produzindo/reproduzindo marcadores como gênero e raça, ao atribuir "significado (identidade, valor, prestígio, posição de parentesco, status dentro da hierarquia social etc.) a indivíduos dentro da sociedade" (LAURETIS, 2004, p.212). Em outras palavras, o clipe utiliza, portanto, de técnicas discursivas e não discursivas que produzem/reproduzem efeitos de sentido em corpos,

\footnotetext{
${ }^{6}$ Ao todo, foram selecionadas 13 obras, entre esculturas e pinturas: A Madona de Ognissanti, de Giotto di Bondone; O nascimento da Vênus, de Sandro Boticelli; Monalisa, de Leonardo da Vinci; A escola de Atenas, de Rafael Sanzio; Flora, de Ticiano; A criação de Adão, de Michelângelo; A Primavera, de Sandro Boticelli; A última ceia, de Leonardo da Vinci; Madona Sistina, de Rafael Sanzio; Retrato de um jovem, de Sandro Boticelli; Davi, de Michelângelo; Retrato de uma jovem mulher, de Sandro Boticelli; Pietá, de Michelângelo.
} 
Dossiê: Ensino de História, História das Mulheres e Desigualdades Sociais no Brasil comportamentos e relações sociais, como bem salienta Teresa de Laurettis. Um discurso que constrói um determinado entendimento, uma orientação, um esquema de interpretação e significação do que seria o papel das artes e o ser negro/negra na contemporaneidade. Junte-se a isso, o fato de música e clipe serem produzidos e protagonizados por um casal negro bem sucedido, como Beyoncé e Jay-Z, interpelando uma audiência inserida em uma região administrativa que, de acordo com os dados de 2018 da Pesquisa Distrital por Amostra de Domicílios, tem $52,8 \%$ de sua população identificada como parda e 12,2\% como negra. (CODEPLAN, 2019, p.13). Ou seja, não se pode desconsiderar a representatividade dos protagonistas daquela produção para nossos/nossas estudantes.

Muito foi dito a época do lançamento sobre a música, uma celebração ao sucesso e ao lugar alcançado por um casal afro-americano e, sobretudo, do clipe, que dialoga diretamente com a história da arte. ${ }^{7}$ Gravada inteiramente no Museu do Louvre, um dos maiores museus do mundo e um dos espaços mais simbólicos da arte ocidental, a produção revela uma crítica contundente a uma produção artística feita por homens brancos, sobre homens brancos e para homens brancos ao longo da história. Nesta crítica, observamos aquele espaço eminentemente branco, masculino e eurocêntrico ser ocupado por corpos negros, majoritariamente femininos, em uma celebração da arte e da cultura afroamericana. Corpos que, como evidencia uma das sequências do clipe, nas artes, estão na penumbra das pinturas expostas, quase não são vistos; no museu, estão no subsolo, em trabalhos pouco valorizados.

Estas representações, em que homens e mulheres negros aparecem em posições de subalternidade, denunciados pelo clipe, expõem a construção da

\footnotetext{
${ }^{7}$ Algumas das matérias veiculadas na época do lançamento do clipe: "Apeshit": o clipe cheio de significados de Beyoncé e Jay-Z Disponível em: https://casavogue.globo.com/Colunas/Arte-doCinema/noticia/2018/06/apeshit-o-clipe-cheio-de-significados-de-beyonce-e-iay-z.html; detalhes de 'Apeshit', clipe de Beyoncé e Jay-Z, que talvez você tenha perdido. Disponível em: https://www.huffpostbrasil.com/2018/06/19/7-detalhes-de-apeshit-clipe-de-beyonce-e-jay-z-quetalvez-voce-tenha-perdido a 23462851/; Beyoncé e Jay-z desafiam a arte ocidental em clipe de "Apeshit". Disponível em: https://rollingstone.uol.com.br/noticia/beyonce-e-jay-z-desafiam-arteocidental-em-clipe-de-apeshit/; Jay-Z e Beyoncé se afirmam não só entre elites financeiras, mas também culturais. Disponível em: https://www1.folha.uol.com.br/ilustrada/2018/06/jay-z-ebeyonce-se-afirmam-nao-so-entre-elites-financeiras-mas-tambem-culturais.shtml; Com o vídeo de 'Apeshit', Beyoncé e Jay-Z se reposicionam como obras de arte. Disponível em: https://f5.folha.uol.com.br/colunistas/tonygoes/2018/06/com-o-video-de-apeshit-beyonce-e-jayz-se-reposicionam-como-obras-de-arte.shtml
} 
Dossiê: Ensino de História, História das Mulheres e Desigualdades Sociais no Brasil diferença racial e as hierarquias advindas de tal construto, bem como a naturalização das desigualdades provenientes de tais relações de poder. Nesta direção, não é difícil perceber as implicações pedagógicas da leitura do videoclipe. Ela se alinha com uma proposta em que, como afirma Tomaz Tadeu da Silva, a pedagogia e o currículo "deveriam ser capazes de oferecer oportunidades para que as crianças e os/as jovens desenvolvessem capacidades de crítica e questionamento dos sistemas e das formas dominantes de representação da identidade e da diferença." (SILVA, 2014, p.91). Sendo assim, a proposta de leitura e análise desse discurso audiovisual nos permite avançar em um debate cada vez mais necessário e urgente, desnaturalizando uma suposta inferioridade negra. Lógica que o clipe também pretende inverter, ao evidenciar corpos que tomam posse do Louvre por meio da música e da dança, de suas contribuições artísticas.

Orientados por tais discussões, avançamos na execução da proposta e chegamos a sua última etapa: a de construção de narrativas outras, em que histórias múltiplas e plurais se fizessem visíveis. Assim, reunidos em grupos, os/as estudantes foram desafiados a elaborar releituras de obras renascentistas a partir de referências africanas e afro-brasileiras, compartilhadas e debatidas ao longo das aulas de história. Dentre elas, figuras como Machado de Assis, André Rebouças, Zumbi dos Palmares, Dandara, Luiza Mahin; de rainhas negras, como Cleópatra, Nefertiti, Nefertari e Nzinga Mbande; espaços de saber e de sociabilidade, como a Universidade de Tombuctu e o samba da Tia Ciata; as religiões de matriz africana, além de figuras de nossa história mais recente, como Carolina Maria de Jesus e Marielle Franco. Histórias que enfatizam, além da resistência dos/das africanos/as e seus descendentes à escravização, as diferentes formas de se organizar, manifestar as suas culturas e a riqueza, diversidade e complexidade das sociedades africanas e suas contribuições para a formação da sociedade brasileira. Afinal, por muito tempo a participação de africanos e africanas e de seus descendentes na formação sociocultural do Brasil foi reduzida, na maioria das vezes, à força de trabalho compulsória, desconsiderando outras contribuições, tais como as formas de organização familiar, a religiosidade, a língua, dentre outras (MATTOS, 2007, p.13). 


\section{HISTÓRIA}

Dossiê: Ensino de História, História das Mulheres e Desigualdades Sociais no Brasil

A partir destas e de outras referências, os trabalhos foram sendo construídos a partir de uma dupla preocupação: a construção da narrativa visual e de legendas que orientassem a leitura das narrativas propostas. O resultado foram 51 trabalhos organizados na exposição "Releituras renascentistas sob uma perspectiva afro-brasileira", aberta à comunidade escolar.
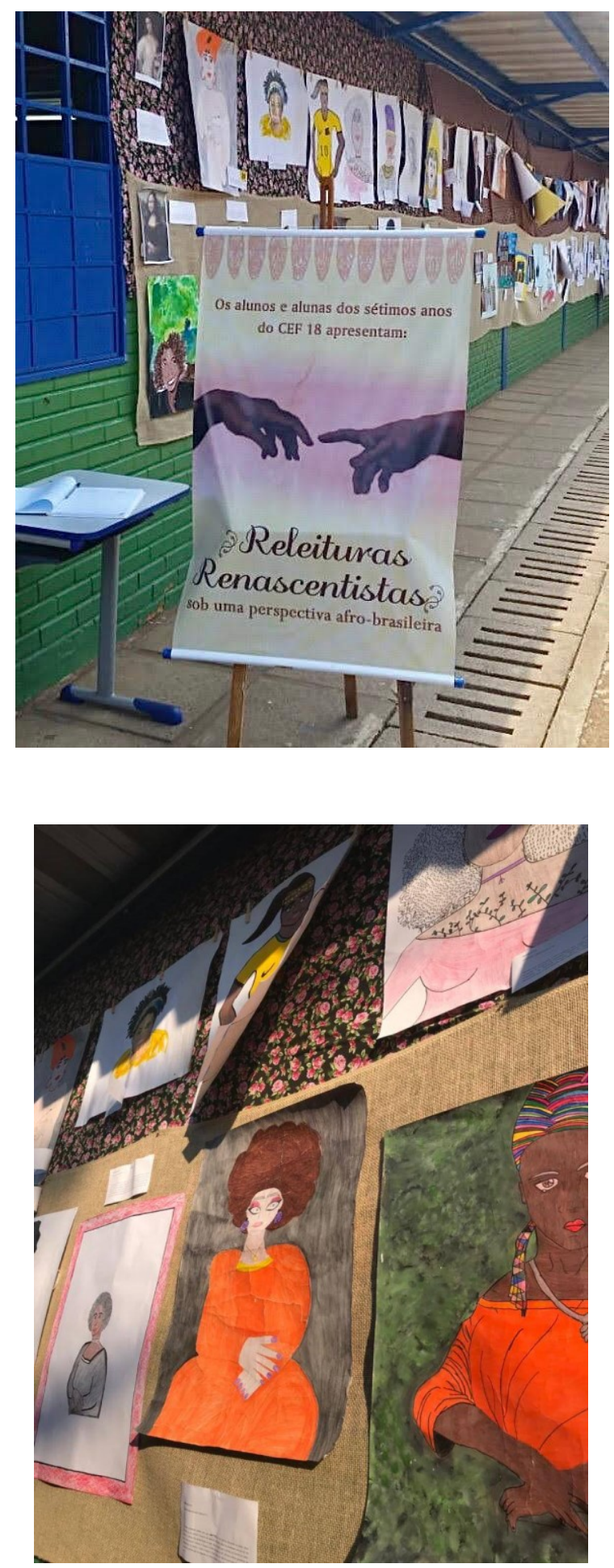


\section{HISTÓRIA}

Dossiê: Ensino de História, História das Mulheres e Desigualdades Sociais no Brasil

Detalhes da exposição. Fonte: arquivo pessoal.

Dentre os trabalhos expostos, o intitulado $A$ fuga, inspirado na obra renascentista $O$ nascimento da Vênus, do artista italiano Sandro Boticelli, executado por duas alunas do $7^{\circ}$ ano $\mathrm{B}$ :

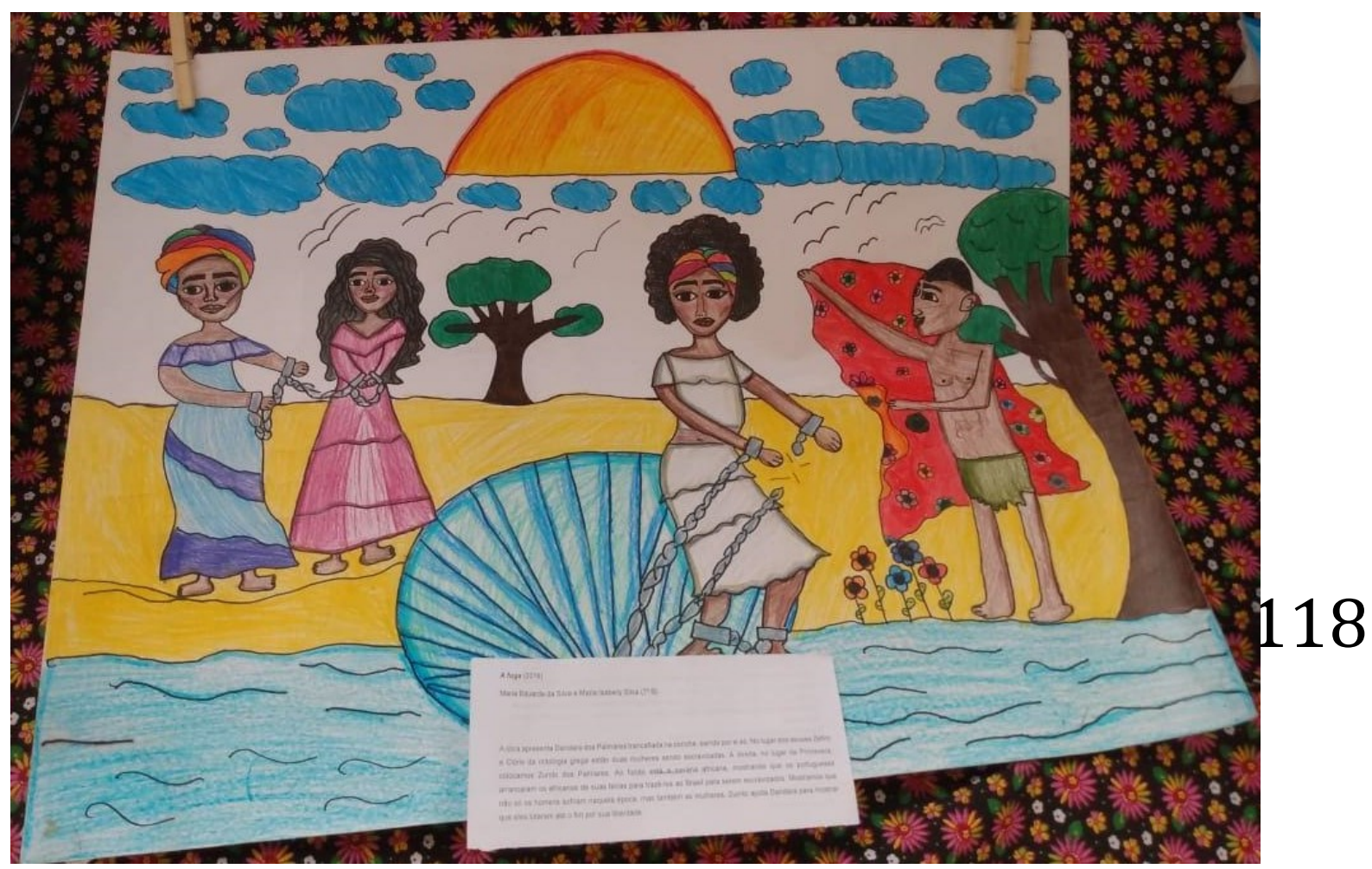

A fuga. Fonte: arquivo pessoal.

No original de Sandro Boticelli, a representação de Vênus, deusa do amor e da beleza na mitologia grega, que emerge das águas, dentro de uma concha, rodeada por Zéfiro (vento oeste) e Clóris (ninfa) por um lado, e de uma Hora (deusa das estações), segurando um manto de outro. Na releitura proposta, as alunas evidenciam a centralidade de Dandara, figura relacionada a um dos maiores símbolos de resistência ao sistema escravista colonial, o quilombo dos Palmares. Na legenda elaborada pelas alunas, percebe-se os sentidos por elas construídos:

A obra apresenta Dandara dos Palmares trancafiada na concha, saindo por si só. No lugar dos deuses Zéfiro e Clóris da mitologia grega estão duas mulheres sendo escravizadas. À direita, no lugar da Primavera, colocamos Zumbi dos Palmares. Ao fundo 
Dossiê: Ensino de História, História das Mulheres e Desigualdades Sociais no Brasil

está a savana africana, mostrando que os portugueses arrancaram os africanos de suas terras para trazê-los ao Brasil para serem escravizados. Mostramos que não só os homens sofriam naquela época, mas também as mulheres. Zumbi ajuda Dandara para mostrar que eles lutaram até o fim por sua liberdade.

Uma narrativa que investe no protagonismo de mulheres negras, na agência feminina e na visibilidade de suas práticas. As alunas ressaltam que Dandara saía da concha, buscava a liberdade "por si só", em uma clara referência às amarras da escravidão. Imagem reforçada pelas correntes quebradas por Dandara, sem nenhum auxílio, numa alusão ao seu protagonismo. Este é reforçado pela imagem de Zumbi, que aguarda a sua libertação, segurando um manto. Mais do que simplesmente companheira de Zumbi, aguardando por suas ações, nesta narrativa Dandara adquire centralidade e tem a mesma importância daquela figura. Sua luta parece, enfim, inspirar outras mulheres escravizadas, representadas à esquerda na imagem.

A releitura elaborada pelas estudantes dialoga diretamente com a crítica às interpretações que enfatizam que mulheres escravizadas seriam desprovidas de qualquer capacidade de ação e atuação, de criar estratégias de lutas para enfrentar o domínio senhorial. Expõe os limites de discursos que encerram as práticas de resistência daquelas mulheres em roteiros preestabelecidos:

a acomodação ao cativeiro; a espera pela alforria; a fragilidade física, a maternidade e o cuidado com a família como limites às suas ações rebeldes. Formas de atuação, ou, em muitos casos, a ausência desta que, de possibilidades, se transformam em verdades acerca do comportamento feminino no cotidiano escravo. São interpretações assentadas sobre um incontornável destino biológico, uma suposta "natureza feminina" imutável, ahistórica, que exclui formas outras, múltiplas e diversificadas de atuação. (MACENA, 2015, p.153).

Como destacamos em outra oportunidade, as mulheres escravizadas lutaram por liberdade, recorrendo a estratégias diversas para alcançá-la e suas histórias indicam a complexidade da vida e das ações de pessoas escravizadas (MACENA, 2015).

Assim como esta releitura confere novos sentidos à vida de mulheres escravizadas, construindo outras representações sobre suas práticas e 


\section{HISTÓRIA}

Dossiê: Ensino de História, História das Mulheres e Desigualdades Sociais no Brasil

enfatizando seu protagonismo, os demais trabalhos vão nessa mesma direção, apontando outras narrativas possíveis. Sublinham o exercício da maternidade das amas de leite, suas dores e seu papel na sociedade brasileira oitocentista; substituem as madonnas cristãs por mulheres de carne e osso, como Carolina Maria de Jesus e Sabina, mãe de Zumbi dos Palmares; propõem outras referências estéticas do belo e um olhar sobre os feitos femininos, como no destaque dado às rainhas africanas. Mas também apontam para novas possibilidades de construção do social, a partir de referenciais contemporâneos. É o que percebemos na releitura Marielle e a criação, elaborada por uma dupla do $7^{\circ}$ ano $\mathrm{F}$ :

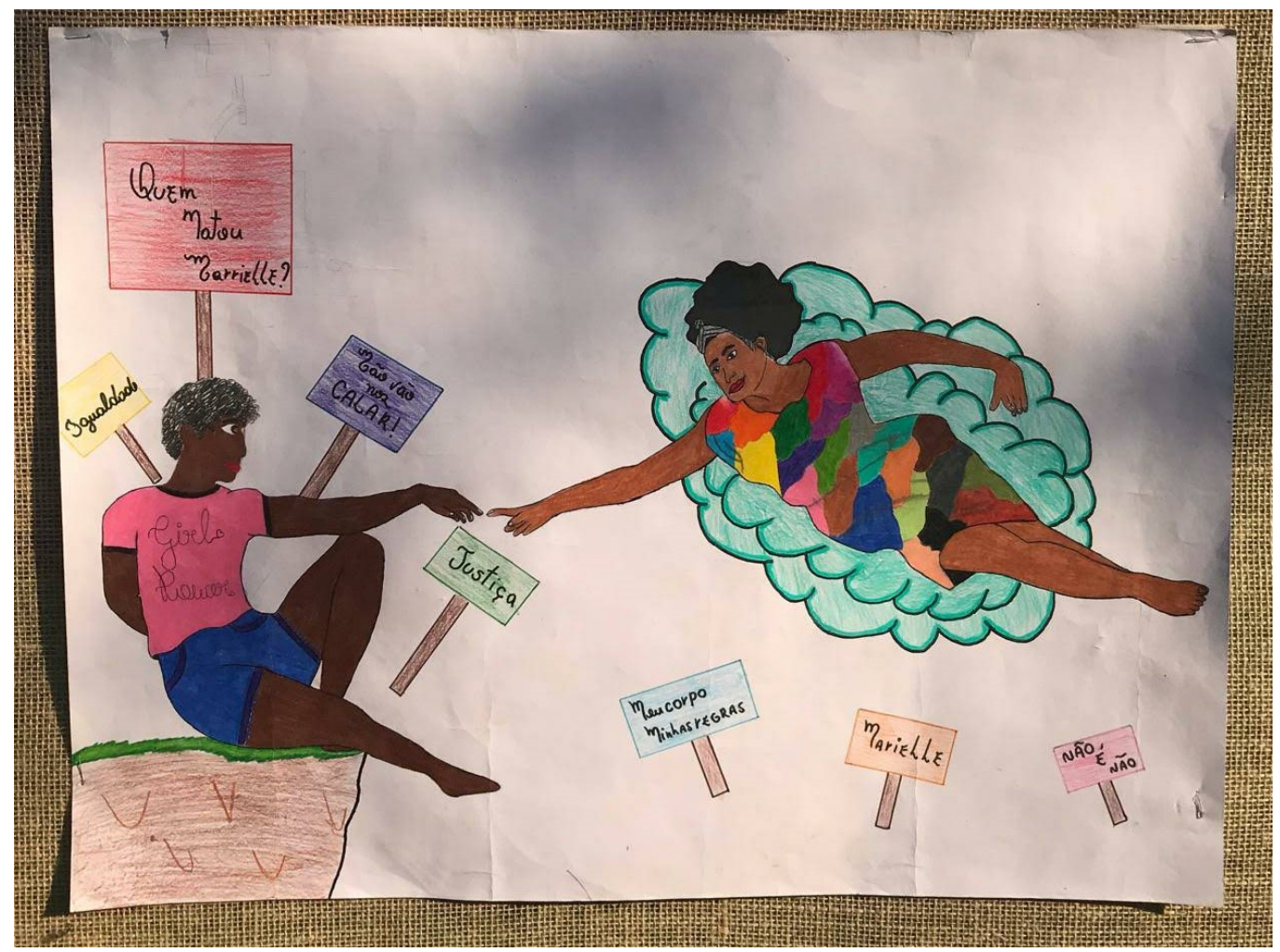

Marielle e a criação. Fonte: arquivo pessoal.

Inspirada no afresco $A$ criação de Adão, de Michelangelo, a releitura proposta pela dupla subverte a representação cristã inspirada no livro bíblico do Gênesis presente no original. Deus é substituído por uma mulher negra, assim como a figura de Adão. Nas mudanças que operam, os estudantes imprimem novos sentidos a imagem. Criar torna-se verbo conjugado no feminino, mostrando o diálogo da releitura proposta com as lutas recentes de mulheres negras, conforme indica a legenda elaborada: 


\begin{abstract}
Nossa obra fala sobre as mulheres, principalmente as negras. Mas de todas essas mulheres, o nosso foco está em Marielle Franco, que foi socióloga, vereadora, feminista e defensora dos direitos humanos. Nesta obra ela está representada como uma deusa que, com o dedo indicador, aponta para uma mulher que representa todas as mulheres negras. É como se Marielle estivesse passando uma mensagem para as mulheres se unirem para defender seus direitos. Na imagem também há cartazes que são como vozes de todas as mulheres para a sociedade.
\end{abstract}

A releitura tem como figura central a vereadora carioca Marielle Franco. Com o braço estendido, ela dá a vida a um movimento, representado por uma mulher negra vestida com uma camiseta com os dizeres Girl Power. Nos cartazes espalhados pela imagem, emergem pautas como a igualdade de direitos, o respeito ao corpo e às demandas de mulheres, bem como o clamor por justiça.

A escolha da protagonista é emblemática. Marielle Franco foi assassinada em março de 2018 em uma emboscada. Sua morte ainda guarda questionamentos (quem mandou matar? Por quê?) e tornou-se símbolo de diferentes lutas: pelos direitos humanos, contra a violência policial, pelo fim da violência contra as mulheres (sobretudo negras) e contra o genocídio da população negra. Pautas que se mostram urgentes, haja vista a grande desigualdade racial existente nos indicadores de violência no Brasil. Conforme destaca o Atlas da Violência 2019, no período entre 2007 e 2017, 75,5\% das vítimas de homicídios no país foram indivíduos negros, "sendo que a taxa de homicídios por 100 mil negros foi de 43,1, ao passo que a taxa de não negros (brancos, amarelos e indígenas) foi de 16,0." (ATLAS, 2019, p.49). Ou seja, em dez anos, tornaram-se maiores as chances de um negro ser vítima de homicídio do que um não-negro. Violência que também atinge diretamente as mulheres negras. O Anuário Brasileiro de Segurança Pública 2019 revela que elas são $61 \%$ das vítimas de feminicídio no país, contra $38,5 \%$ de brancas, $0,3 \%$ indígenas e 0,2\% amarelas (ANUÁRIO, 2019, p.111).

São dados que sublinham a persistência de práticas discriminatórias em nossa sociedade, assentadas sobre o entendimento das diferenças físicas como desigualdades, ao representar a população negra como o "outro", como 


\section{HISTÓRIA}

Dossiê: Ensino de História, História das Mulheres e Desigualdades Sociais no Brasil

naturalmente inferior. Práticas que criam e reafirmam hierarquias, tornadas naturais, e limitam o pleno acesso aos direitos, a partir da "prevalência da concepção de que certos humanos são mais ou menos humanos do que outros" (CARNEIRO, 2011, p.15).

Todavia, a releitura apresentada pelos estudantes revela uma outra representação, uma outra imagem possível: a de mulheres negras como sujeitos políticos, em suas lutas pelo direito a ter direitos. Que encontram novas possibilidades de existência e resistência na mobilização coletiva e que, como lembra Djamila Ribeiro, movem-se para além da dor, para além das marcas da violência. Afinal, ainda com aquela autora, por mais que seja assim, "posto que a sociedade é estruturada por racismo, machismo e capitalismo, muitas trazem a importância de encontrarmos nossas próprias definições." (RIBEIRO, 2019). Trata-se de ver as múltiplas formas de agenciamento de suas vidas, observando que,

Entre a vitimização e a produção simbólica de heróis, há experiências complexas de luta, opressão, humilhação, superação, amor, dor, desejos, escolhas, alegrias e desafios. Constatar isso pode ser pouco. Mais importante será conhecer e tornar visível - em alguns espaços do conhecimento e da decisão sobre as políticas públicas - o universo das mulheres negras e o seu protagonismo de ontem e de hoje. (PAIXÃO e GOMES, 2012, p.311).

Considerações finais

Ao tornar visível (e dizível) narrativas sobre mulheres negras, enfatizando os seus protagonismos, as/os estudantes constroem outros percursos no processo de ensino-aprendizagem: destronam ídolos da memória social, produzem outras representações, criam possibilidades de leitura do social e se tornam agentes do processo de produção do conhecimento histórico escolar. Mais do que investir em um adendo à história, inserir a parte que até então faltava, as discussões sobre gênero e raça permitem questionar os termos do próprio conhecimento histórico escolar, seus silêncios discursivamente produzidos, seu esforço homogeneizador. Além disso, a referência àqueles marcadores permite compreender o modo como diferenças são construídas, 
Dossiê: Ensino de História, História das Mulheres e Desigualdades Sociais no Brasil significadas e transformadas em desigualdades, assim como o seu funcionamento nas relações sociais.

No exercício do pensamento e reflexão crítica dos/das educandos, o investimento na formação de cidadãos e cidadãs atuantes na sociedade em que vivem, que possam agir como sujeitos de suas próprias vidas e histórias. Particularmente, se entendemos a noção de cidadania menos pela necessidade de formação de patriotas do que pela possibilidade de estimular cidadãos e cidadãs autônomos, comprometidos com a sociedade e aptos a decidir com liberdade o futuro que querem para si e para o mundo (PAGÈS, 2011: 18). Um futuro em que, espera-se, haja espaço para todas as formas de existência e que sejam subvertidas as situações de desigualdade vivenciadas por diferentes sujeitos.

Tais reflexões permitem-me, portanto, voltar ao início deste artigo e precisar o meu "lugar social" e minha "topografia de interesses", para retomar as formulações de Michel de Certeau (CERTEAU, 2011). Assumo minha posição de professora/pesquisadora, que compreende o seu fazer como mediação no processo de produção do conhecimento histórico escolar e que, ao mesmo tempo, pesquisa a sua própria prática docente. Mais do que objeto de pesquisa, o ensino de história é espaço que ocupo e lugar de onde falo. Encontro-me envolvida no processo de ensino-aprendizagem de história, ao mesmo tempo em que leio a ação dos/das estudantes, agentes neste processo e a minha própria prática, ciente da dimensão política desta.

Ciente disso, oriento-me, cada vez mais, por uma história pensada e ensinada como possibilidade, aberta ao múltiplo, ao diferente, ao diverso, ao instável, que reconheça e valorize as experiências de diferentes atores sociais, seus lugares de fala e posição de sujeitos. E que também considere os anseios e os questionamentos das/dos estudantes. Afinal, não há ensino de História desenraizado da realidade e muito menos desvinculado de aspectos socioculturais de nossa contemporaneidade. Sendo assim, faz-se necessário pensar práticas educativas que priorizem questões presentes no cotidiano de nossos/nossas estudantes e que os/as coloquem no centro do processo de construção do conhecimento histórico escolar. 


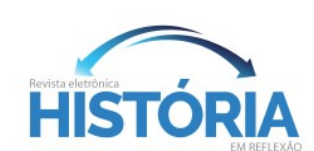

Dossiê: Ensino de História, História das Mulheres e Desigualdades Sociais no Brasil

\section{REFERÊNCIAS}

ALBUQUERQUE JR., Durval Muniz de. História: a arte de inventar o passado. Ensaios de teoria da história. Bauru, SP: EDUSC, 2007. p.185.

ANUÁRIO Brasileiro de Segurança Pública 2019. São Paulo: ano 13, 2019.

ATLAS da Violência 2019. Brasília: Rio de Janeiro: São Paulo: Instituto de Pesquisa Econômica Aplicada; Fórum Brasileiro de Segurança Pública, 2019.

AZERÊDO, Sandra. Teorizando sobre gênero e relações raciais. Estudos Feministas, out. 1994. p. 203-216.

CARNEIRO, Sueli. Racismo, sexismo e desigualdade no Brasil. São Paulo: Selo Negro, 2011.

CARRETERO, Mario; ROSA, Aberto; GONZÁLEZ, María Fernanda. Introducción: Enseñar historia en tiempos de memoria. CARRETERO, Mario; ROSA, Aberto; GONZÁLEZ, María Fernanda (orgs.). Enseñanza de la historia y memoria coletiva. Buenos Aires: Paidós, 2006.

CARVALHO, Andréa Aparecida de Moraes Cândido de. As imagens de negros em livros didáticos de História. 139 f. Dissertação (Mestrado). Programa de Pós-Graduação em Educação, Universidade Federal de Santa Catarina, Florianópolis, 2015.

CERTEAU, Michel. A escrita da história. $3^{a}$. ed. Rio de Janeiro: Forense, 2011.

CODEPLAN (Companhia de Planejamento do Distrito Federal). PDAD 2018: Pesquisa Distrital por Amostra de Domicílios. Brasília, 2019.

FONSECA, Selva Guimarães. Caminhos da história ensinada. Campinas: Papirus, 1993.

FOUCAULT, Michel. Microfísica do poder. $24^{\mathrm{a} e d .}$ Rio de Janeiro: Edições Graal, 2007.

GOMES, Nilma Lino. A questão racial na escola: desafios colocados pela implementação da Lei 10.639/03. In: MOREIRA, Antônio Flávio e CANDAU, Vera (orgs). Multiculturalismo: diferenças culturais e práticas pedagógicas. Petrópolis/RJ: Editora Vozes, 2008.

GUIMARÃES, Antônio Sergio Alfredo. Raça e os estudos das relações raciais no Brasil. Novos Estudos CEBRAP, n. 54, jul. 99. p. 147-156.

GUIMARÃES, Manoel Luiz Salgado. Escrever a história, domesticar o passado. In: LOPES, Antonio Herculano; VELLOSO, Monica e PESAVENTO, Sandra Jatahy (orgs.). História e linguagens: texto, imagem, oralidade e representações. Rio de Janeiro: 7 Letras, 2006. 


\section{HISTÓRIA}

Dossiê: Ensino de História, História das Mulheres e Desigualdades Sociais no Brasil

JODELET, Denise. Representações Sociais: um domínio em expansão. In: JODELET, Denise (org.). As representações sociais. Rio de Janeiro: EdUERJ, 2001.

LAURETIS, Teresa de. A tecnologia de gênero. In: HOLANDA, Heloísa B. De (org.). Tendências e impasses: o feminismo como crítica da cultura. Rio de Janeiro: Rocco, 2004.

MACENA, Fabiana Francisca. Outras faces do abolicionismo em Minas Gerais: rebeldia escrava e ativismo de mulheres. 294 f. Tese (Doutorado). Programa de Pós-Graduação em História, Universidade de Brasília, DF, 2015.

MATTOS, Regiane Augusto de. História e cultura afro-brasileira. São Paulo: Contexto, 2007.

MESQUITA, Natiele Gonçalves e SCHIAVON, Carmem G. Burgert. Análise das representações de negros e negras em dois livros didáticos de História.

Identidade, São Leopoldo, v.18, n.3, ed. especial, dez. 2013. p.334-344.

MONTEIRO, Ana Maria. Ensino de História: entre história e memória. In:

AZEVEDO, Patrícia Bastos de. Pesquisa e Prática educativa: os desafios da pesquisa no Ensino de História. Rio de Janeiro: EDUR, s/d. Disponível em: http://www.ufrri.br/graduacao/prodocencia/publicacoes/pesquisa-praticaeducacional/default.html Acesso em: 29 mai. 2020.

MONTEIRO, Paolla Ungaretti. (In)visibilidade das mulheres brasileiras nos livros didáticos de história do Ensino Médio (PNLD, 2015). $228 \mathrm{f}$.

Dissertação (Mestrado). Escola de Humanidades, Pontifícia Universidade Católica do Rio Grande do Sul, Porto Alegre, 2016.

MUNIZ, Diva do Couto Gontijo. A formação de professores: os espaços da pósgraduação e da graduação. In: FONSECA, Selva Guimarães e GATTI JÚNIOR, Décio (orgs.). Perspectivas do Ensino de História: ensino, cidadania e consciência histórica. Uberlândia: EDUFU, 2011.

NEPOMUCENO, Bebel. Mulheres negras: protagonismo ignorado. In: PINSKY, Carla Bassanezi e PEDRO, Joana Maria (orgs.). Nova História das mulheres. São Paulo: Contexto, 2012.

OLIVEIRA, Susane Rodrigues. In: STEVENS, Cristina; OLIVEIRA, Susane Rodrigues e ZANELLO, Valeska (orgs.). Estudos Feministas e de Gênero: articulações e perspectivas. Florianópolis: Editora Mulheres, 2014.

PAGĖS, Joan. Educación, ciudadanía y enseñanza de la Historia. In: FONSECA, Selva Guimarães e GATTI JÚNIOR., Décio (orgs.). Perspectivas do Ensino de História: ensino, cidadania e consciência histórica. Uberlândia:

Edufu, 2011. p.17-31. 


\section{HISTÓRIA}

Dossiê: Ensino de História, História das Mulheres e Desigualdades Sociais no Brasil

PAIXÃO, Marcelo e GOMES, Flávio. Histórias das diferenças e das desigualdades revisitadas: notas sobre gênero, escravidão, raça e pósemancipação. In: XAVIER, Giovana; BARRETO, Juliana e GOMES, Flávio (orgs.). Mulheres negras no Brasil escravista e do pós-emancipação. São Paulo: Selo Negro, 2012.

RIBEIRO, Djamila. Mover-se para além da dor. Portal Gelédes, 08 set. 2019. Disponível em: https://www.geledes.org.br/mover-se-para-alem-da-dor/ Acesso em: 13 jun. 2020.

RICCI, Cláudia Sapag. Pesquisa como ensino. Textos de apoio. Propostas de trabalho. Belo Horizonte: Autêntica, 2007.

SANTOS, Sales Augusto dos. A lei n. 10.639/03 como fruto da luta anti-racista do movimento negro. In: Educação anti-racista: caminhos abertos pela Lei Federal n 10.639/03. Brasília/DF: MEC/Secretaria de Educação Continuada, Alfabetização e Diversidade, 2005.

SCOTT, Joan. Gênero: uma categoria útil de análise histórica. Educação e Realidade, Porto Alegre, v. 16, n. 2, jul./dez., 1990.

SILVA, Tomaz Tadeu da Silva. A produção social da identidade e da diferença. In: SILVA, Tomaz Tadeu da Silva (org.). Identidade e diferença: a perspectiva dos estudos culturais. 15ª . ed. Petrópolis, RJ: Vozes, 2014.

SOUZA, Marina de Mello e. Algumas impressões e sugestões sobre o ensino de História da África. Revista História Hoje. São Paulo, v.1, n.1, 2012. p.1728. 